\title{
The growth of Escherichia coli in a food simulant during conduction cooling: combining engineering and microbiological modelling
}

\author{
Sanjay R. Bellara, C. M. McFarlane, C. R. Thomas, P. J. Fryer* \\ School of Chemical Engineering, The University of Birmingham, Edgbaston, Birmingham B15 2TT, UK \\ Received 10 December 1999; accepted 12 June 2000
}

\begin{abstract}
Several studies have been conducted over the last decade to accumulate data on the growth of food-borne bacteria as a function of different environmental variables, such as temperature or $\mathrm{pH}$. It has been demonstrated that such data can be used to predict bacterial growth in food products, both under conditions of constant and fluctuating temperatures. The purpose of the present study was to combine bacterial growth modelling with a heat transfer model describing the spatial temperature changes within a solid object, and to validate the model experimentally. Firstly, experimental growth data were attained for Escherichia coli W3110 immobilised in agar at fixed temperatures. Growth data were then fitted using predictive microbial models to represent growth in lag, exponential and stationary phases. When compared to growth in liquid cultures, similar values were found for maximum exponential growth rate. Next, experiments were conducted whereby a 91 vessel was filled with agar inoculated with E.coli and conduction cooled in a water bath. A finite difference scheme was used to model heat transfer from the vessel, and bacterial growth was consequently modelled as a function of temperature inside the vessel. Experimental results for bacterial growth showed good agreement with theory. The results show that it is feasible to combine engineering and microbial models. (C) 2000 Elsevier Science Ltd. All rights reserved.
\end{abstract}

Keywords: Predictive microbiology; Heat transfer; Escherichia coli

\section{Introduction}

Incidences of food-borne illnesses are a problem of growing international concern. In the United Kingdom, for example, the number of incidences of food poisoning has increased almost 10-fold between 1977 and 1997, to 94,000 cases (Communicable Disease Surveillance Centre, Public Health Laboratory Service, 1998). The bulk of these cases was attributed to meat, poultry, eggs and red meat products (Adams \& Moss, 1995). Strains of Escherichia coli were first recognised as a cause of gastroenteritis in the early 1940s, and more recently, owing to a number of fatal outbreaks, E.coli 0157:H7 (a particularly virulent strain) has become well established as a food-borne pathogen (Jay, 1996).

Advances in techniques for the development and application of mathematical models to predict the growth of micro-organisms in foods have resulted in the emergence of a new discipline called predictive microbiology

\footnotetext{
*Corresponding author. Tel.: + 44-121-414-5451; fax: + 44-121414-5324.

E-mail address: p.j.fryer@birmingham.ac.uk (P. J. Fryer).
}

(Skinner, Larkin \& Rhodehamel, 1994). Typically, a two-step approach has been used in this type of modelling. In the first, curves are fitted to data derived experimentally, whilst in the second, kinetic parameters derived from the curve-fitting procedure have been modelled with respect to the different environmental variables tested (such as $\mathrm{pH}, a_{\mathrm{w}}$, temperature) (McClure et al., 1994a). There are a number of examples in the literature describing the application of these models to bacterial growth data (e.g. Buchanan, Bagi, Goins \& Philips, 1993; McClure, Cole \& Davies, 1994b). The potential benefits of predictive microbiology to the food industries have been outlined in a number of studies. For example, by mathematically modelling the growth of bacteria, it has been shown possible to obtain a reasonably good estimation of the shelf-life of fish products (McMeekin, Ross \& Olley, 1992; Dalgaard, 1995), dairy products (Griffiths, 1994), and also to be able to predict the growth of the pathogen E.coli 0157:H7 in raw ground beef (Walls $\&$ Scott, 1996). However, as pointed out by Zwietering, de Wit and Notermans (1996), predictive microbiology will only estimate bacterial growth to within orders of magnitude. Such modelling, although useful in enabling 
one to detect hazards during product handling and storage, is not able to provide accurate information on the changes in microbial flora in food products.

Mathematical modelling of bacterial growth has been extended to enable prediction of the increase in bacterial numbers when they are exposed to fluctuating temperatures. This typically involves the use of some temperature function that describes bacterial growth rate (and sometimes lag time as well) in terms of temperature. Differential expressions for bacterial growth as a function of time and temperature can be numerically integrated over the course of an experiment using the temperature function to vary growth parameters. In spite of the fact that the models available in the literature for integrating bacterial growth vary greatly in their degree of complexity, there are several reports of such modelling showing good agreement with experimental data (Mitchell, Brocklehurst, Parker \& Smith, 1994; Zwietering, de Wit, Cuppers \& van’t Riet, 1994; Baranyi, Robinson, Kaloti \& Mackey, 1995). Instances where experimental data did not agree with modelling were when temperature fluctuations were either too rapid or too great in magnitude for bacteria to be able to adapt physiologically. Such techniques have also been demonstrated to be effective in modelling bacterial growth during the chilling of lean beef (Dickson, Siragusa \& Wray, 1992), storage of dairy products ( $\mathrm{Fu}$, Taoukis \& Labuza, 1991) and industrial chilling of meat carcasses (Gill, 1996).

In spite of all the advances made in modelling microbial growth, there are relatively few studies that combine these developments with heat transfer modelling to describe the varying temperature profile throughout food products as they are heated or cooled. Some packaged food products, such as boxed sausages, will have bacteria growing within the food product, as opposed to freshly slaughtered meat carcasses where growth is restricted to the surface (Gill, Friske, Tong \& McGinnis, 1994). Almonacid-Merino and Torres (1993) combined numeric modelling of the heat transfer equations with a microbial growth model to predict the shelf-life of refrigerated solid foods undergoing temperature abuse. However, that study was limited to purely mathematical modelling. In an engineering sense, it is critical to combine prediction of the growth of bacteria within foods with the prediction of temperature in the process. It is not clear however if the variation in temperature seen during processing is sufficiently rapid to invalidate the models. Predictive microbial equations are essentially correlations, a concept familiar to chemical engineers. A soundly based correlation (for example, the van der Waals equation) enables experimental data to be modelled using the smallest number of parameters. Predictive microbiology seeks similar approaches: a model which represents reality in as simple a way as possible, using as few adjustable parameters as possible.
The purpose of this study is to determine whether predictive microbiology can be combined with heat transfer modelling. E.coli $\mathrm{W} 3110$ has been used as a model bacterium. This is an important food poisoning organism; the strain used here is non-pathogenic, but is physiologically similar to the pathogenic strains. Experiments used agar inoculated with bacteria within a glass vessel, which was then cooled by conduction in a water bath. Experimental results for bacterial growth have been compared to mathematical models of that growth.

\section{Mathematical modelling}

\subsection{Modelling microbial growth}

Traditionally, in food microbiological studies, bacterial growth is represented by a plot of the logarithm of cell numbers against time and fitted using a sigmoidal function such as Gompertz or logistic (Gibson, Bratchell \& Roberts, 1988; Zwietering, Jongenburger, Rombouts $\&$ van't Riet, 1990). This study used the model of Baranyi et al. (1995) to fit experimental data for the growth of E.coli when grown at a constant temperature. This model uses a more mechanistic basis for the description of bacterial growth and has been shown to provide a superior fit to experimental data for bacterial growth when compared to the commonly used sigmoidal functions (Baranyi, Roberts \& McClure, 1993; Baranyi et al., 1995). In this model, it is assumed that the specific growth rate during the lag phase is controlled by the per cell quantity of a substance, $P(t)$. After inoculation, a constant specific growth rate $(v)$ is assumed for the growth of this substance:

$\frac{\mathrm{d}}{\mathrm{d} t} P=v P$.

Furthermore, it is assumed that $P(t)$ controls growth rate according to Michaelis-Menten-type kinetics (see Eq. (2)). During exponential growth, the quantity of this critical substance will have increased to a point where it is no longer limiting. To describe the transition from exponential to stationary phase, a logistic-type limiting function $\left(1-\mathrm{OD} / \mathrm{OD}_{\mathrm{MAX}}\right)$ is applied to reduce growth rate. These factors can be assembled into a single equation to describe the increase in bacterial optical density:

$\frac{\mathrm{d}}{\mathrm{d} t} \mathrm{OD}=\mu(T) \frac{P}{K_{P}+P}\left(1-\frac{\mathrm{OD}}{\mathrm{OD}_{\mathrm{MAX}}}\right) \mathrm{OD}$,

where OD is the optical density at time $t, \mathrm{OD}_{\mathrm{MAX}}$ is the maximum optical density attained in the stationary phase, $\mu$ is the maximum exponential growth rate and $K_{P}$ is a Michaelis-Menten-type constant. As an initial condition, $\mathrm{OD}_{0}$ is the optical density before growth starts; this refers to bacterial amount, as the background 
has been subtracted. The parameter $q(t)$ is used to characterise the physiological state of the culture:

$q(t)=\frac{P(t)}{K_{P}}$.

Eqs. (1) and (2) can hence be rewritten as follows:

$\frac{\mathrm{d}}{\mathrm{d} t} q=v q$

$\frac{\mathrm{d}}{\mathrm{d} t} \mathrm{OD}=\mu(T) \frac{q}{1+q}\left(1-\frac{\mathrm{OD}}{\mathrm{OD}_{\mathrm{MAX}}}\right) \mathrm{OD}$.

The parameter $v$ affects the curvature from lag to midexponential phase. It is assumed that the critical substance will grow at the same rate as cells in the exponential phase, i.e. $v=\mu$. The solution of the above system of equations is as follows (see Baranyi et al., 1993):

$y(t)-y_{0}=\mu A(t)-\ln \left(1+\frac{\mathrm{e}^{\mu A(t)}-1}{\mathrm{e}^{y_{\mathrm{MAx}}-y_{0}}}\right)$,

where $y(t)=\ln \mathrm{OD}, y_{0}=\ln \mathrm{OD}_{0}, y_{\mathrm{MAX}}=\ln \mathrm{OD}_{\mathrm{MAX}}$. The variable $A(t)$ is

$A(t)=t+\frac{1}{\mu} \ln \left(\mathrm{e}^{-\mu t}+\mathrm{e}^{-h_{0}}-\mathrm{e}^{-\mu t-h_{0}}\right)$.

The parameter $h_{0}$ is the product of $\mu$ and the lag time. These two parameters can be fitted to experimental data for bacterial growth. Experiments can be performed at different temperatures under otherwise identical conditions, and for each temperature, a best fit value for $h_{0}$ and $\mu$ found. In the experiments described here, a mean value of $h_{0}$ was taken because $h_{0}$, unlike $\mu$, was not found to vary much with temperature, and a new best fit value for $\mu$ determined using this $h_{0}$ value at each temperature.

The model, as originally presented in the literature (Baranyi et al., 1995), was intended to model the increase in bacterial numbers rather than suspension optical density. For Eq. (6) to continue to be able to provide a good description of bacterial growth, the relationship between optical density and bacterial cell numbers should be approximately linear; something which has been demonstrated to be true for optical densities of around 1.0 or less (Begot, Desnier, Daudin, Labadie \& Lebert, 1996) which is the case here.

\subsection{Predicting growth at changing temperatures}

Using the data obtained for $\mu$ from static temperature experiments, it is necessary to fit them to an equation describing $\mu$ as a function of temperature. Traditionally, many studies have used a simple Arrhenius-based model (or some modification of it), where growth rate increases exponentially with temperature (Skinner et al., 1994).
Daughtry, Davey and King (1994) demonstrated that it was possible to modify this model such that it gives an extremely good fit to experimental data. Ratkowsky, Olley, McMeekin and Ball (1982) proposed a linear relationship between the square root of the growth rate and temperature $(T)$ of the following form:

$\sqrt{\mu}=b\left(T-T_{0}\right)$,

where $b$ is the regression coefficient and $T_{0}$ is the temperature value which is an intrinsic property of the bacteria being tested and is fitted to experimental data. This relationship was found to apply to 43 strains of bacteria up to their optimal growth temperatures. A number of other studies have since demonstrated that Eq. (8) provides an excellent fit to experimental data (Adams, Little \& Easter, 1991; Baranyi et al., 1995; Li \& Torres, 1993). There are also more complicated functions available in the literature which give an accurate description of bacterial growth at temperatures both above and below the optimum (Baranyi et al., 1996; Ratkowsky, Lowry, McMeekin, Stokes \& Chandler, 1983; Zwietering, de Koos, Hasenack, de Wit \& van't Riet, 1991). However, the relatively simple approach outlined here may be adequate for the description of growth as bacteria are exposed to a range of different changing temperatures. Beyond the optimal growth temperature, growth rate decreases slowly for a few degrees Celsius and then rapidly declines. Hence, in the following study, Eq. (8) will be used to describe bacterial growth up to a certain temperature $\left(T_{L}\right)$ after which the following relationship will be used:

$\mu=$ constant,$\quad T>T_{L .}$.

Beyond $T_{L}$ (which is found by experiment) the growth rate will rapidly drop to zero. However, such high temperatures were not used here.

To predict bacterial growth under conditions of changing temperatures using the model of Baranyi et al. (1995) requires the numerical computation of Eqs. (4) and (5) with the following initial values:

$\mathrm{OD}(t=0)=\mathrm{OD}_{0}$,

$q(t=0)=\frac{1}{\mathrm{e}^{h_{0}}-1}$.

The above initial value problem (Eqs. (4), (5), (10) and (11)) can be integrated with respect to time using Eqs. (8) and (9) to give a value for $\mu(T)$ as $T$ varies as a function of time.

\subsection{Modelling temperature change in the vessel}

The temperature profile in the vessel of Fig. 1 can be predicted from the unsteady-state heat conduction equation. For a cylinder, the change in temperature in the 


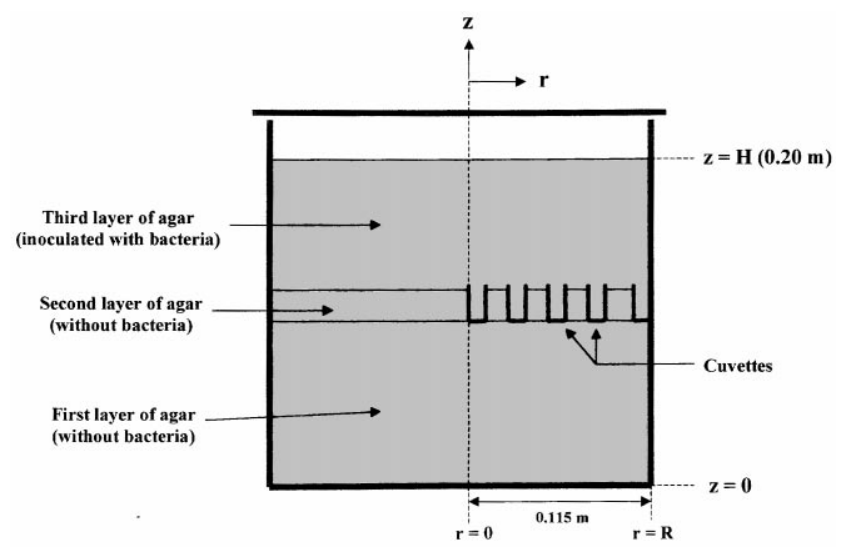

Fig. 1. Schematic outline of the vessel filled with agar as used in the vessel cooling experiments.

vessel over time can be described using (Coulson \& Richardson, 1990)

$\frac{\partial T}{\partial t}=\alpha\left[\frac{1}{r} \frac{\partial}{\partial r}\left(r \frac{\partial T}{\partial r}\right)+\frac{\partial^{2} T}{\partial z^{2}}\right]$

where $\alpha$ is the thermal diffusivity, and $r$ and $z$ are the radial and axial co-ordinates, respectively. Appropriate boundary conditions and physical properties are needed. In the experimental work, described in the next section, the sides and base $(z=0)$ of the vessel are exposed to water. The top of the vessel was covered with a glass lid, however, with some air being trapped between the lid and agar surface. As the agar used is more than $95 \%$ water, a value for $\alpha$ the same as that for water $\left(1.45 \times 10^{-7} \mathrm{~m}^{2} \mathrm{~s}^{-1}\right)$ will be used (Bellara et al., 1999). The borosilicate glass that the vessel was made from has a value of $\alpha$ of $6.3 \times 10^{-7} \mathrm{~m}^{2} \mathrm{~s}^{-1}$ (Perry \& Green, 1984). Eq. (12) was solved using a finite difference scheme using the boundary conditions described below. For heat transfer within a cylindrical object, the following boundary conditions are commonly used:

at $r=0, \quad \frac{\partial T}{\partial r}=0$

and

at $\quad r=R_{T}, z=0, \quad q_{H}=h\left(T_{\text {liquid }}-T_{\text {surface }}\right)$,

where Eq. (14) describes the interfacial heat transfer between the surface and surroundings. In this equation, $q_{H}$ is the heat flux between the surface of the vessel (at temperature $T_{\text {surface}}$ ) and liquid temperature (at temperature $T_{\text {liquid }}$ ), $h$ is the local heat transfer coefficient and $R_{T}$ is the external radius of the vessel. In the present study, cooling is provided by water undergoing forced circulation, so that the cooling rate is controlled by internal conduction and does not depend on the heat transfer coefficient (i.e. the value of $h$ is high). Therefore, the following approximation was used, which has been proven to be valid in another study (Bellara et al., 1999):

at $r=R, z=0, \quad T_{\text {liquid }}=T_{\text {surface }}$.

The agar surface is exposed to entrapped air, and as the heat capacity of air is small relative to that of water, it can be assumed that no heat transfer occurs this boundary. Hence, the following boundary condition was used at this point (where $H$ is the height of the agar in the vessel):

at $\quad z=H, \quad \frac{\partial T}{\partial z}=0$.

\section{Materials and methods}

\subsection{Organism and growth conditions}

Escherichia coli $\mathrm{W} 3110$ was maintained at $-80^{\circ} \mathrm{C}$ on synthetic medium supplemented with $20 \% \mathrm{v} / \mathrm{v}$ glycerol. Cultures of E.coli for growth experiments were prepared as follows: $10 \mathrm{ml}$ of all purpose tryptone (APT) broth (Becton Dickinson and Company, Franklin Lakes, New Jersey, USA) was inoculated with a single loopful of bacterial culture taken from an APT agar (Becton Dickinson and Company) slope and incubated for $6 \mathrm{~h}$ at $37^{\circ} \mathrm{C}$. One $\mathrm{ml}$ of this culture was then used to inoculate $100 \mathrm{ml}$ of fresh APT broth and incubated for a further $22 \mathrm{~h}$ on a shaking platform at $37^{\circ} \mathrm{C}$.

\subsection{Static temperature experiments}

Growth experiments at static temperatures were performed both in APT broth and APT agar. In both instances, bacterial culture was diluted $1: 50$, either in broth which was pre-chilled/heated to the experimental temperature or in molten APT agar at $41^{\circ} \mathrm{C}$. In the instance of the liquid culture experiments, bacterial cultures were placed on a shaking platform (either in an incubator or water bath) and samples were removed periodically and measured for optical density at $600 \mathrm{~nm}$ using a spectrophotometer (Cecil Instruments, Cambridge, UK). If suspension optical density was greater than 1.0, it was diluted to a value less than that. Optical density values (for liquid culture work) are presented as the product of the measured optical density and dilution factor. Experiments with agar were performed by adding $3 \mathrm{ml}$ of the bacterial culture that had been diluted into APT agar into glass cuvettes $(3.5 \mathrm{ml}$ working volume, light path of $10 \mathrm{~mm}$ ) and subsequently allowing the agar to solidify. The cuvettes were then incubated at the test temperature and periodically removed so as to measure optical density (at $600 \mathrm{~nm}$ ). 


\subsection{Vessel cooling experiments}

Cooling experiments were performed using a 91 volume glass cylindrical vessel, with a wall thickness of $3.0 \mathrm{~mm}$ and internal diameter of $0.229 \mathrm{~m}$. A diagram of the vessel is shown in Fig. 1. The vessel was filled with 4.51 molten agar (1.2 $\mathrm{wt} \%$ solution) and left overnight to solidify. Glass cuvettes $(3.5 \mathrm{ml}$ working volume, light path of $10 \mathrm{~mm}$ ) were placed on top of the solidified agar at five different radial points from the centre of the vessel. More molten agar was then poured into the vessel (around the cuvettes) until it almost reached the brim of the cuvettes and was subsequently allowed to solidify. The cuvettes were thus embedded into a solidified agar cylinder. The vessel was then left overnight in a water bath to allow the temperature of the agar to reach a uniform value of $41^{\circ} \mathrm{C}$. The part of the cuvette through which the spectrophotometric beam would pass through (when analysed later on) was positioned in the vessel such that it is at a height of $z=0.625 H$, where $H$ is the total height of the agar in the vessel $(0.20 \mathrm{~m})$. Bacterial culture was diluted 1:50 into 2.41 molten APT agar (temperature in the range $41-42^{\circ} \mathrm{C}$ ) and poured into the vessel over the pre-solidified agar (filling the cuvettes in the process). The vessel was then immediately placed in a circulated cooling water bath and covered with a glass lid for $12 \mathrm{~h}$. Initially, the bacteria-inoculated APT agar is in a liquid state. Ordinarily, when cooling or heating liquids, differences in temperatures within a fluid give rise to density differences and hence convection forces which serve to enhance heat transfer throughout the fluid medium (Raithby \& Hollands, 1998). In this study, modelling convection effects was not necessary as the temperature of the molten agar was just above the temperature at which it solidifies. Hence, as the agar cools it solidifies, and a more turbid (solid) ring or agar could be observed moving inwards towards the centre of the vessel. After cooling, the cuvettes were removed and their optical density measured. All experiments were performed in duplicate and the results proved to be reproducible.

\subsection{Heat transfer model and validation}

Heat transfer in the vessel of Fig. 1 was modelled using a finite difference solution of Eq. (12) with the physical property data noted above and the boundary conditions of Eqs. (13), (15) and (16). The temperature profile thus predicted was then used to calculate the microbial growth rates at the radii and height of each of the sample cuvettes.

To demonstrate that heat transfer from the vessel is accurately described by the use of this model, an agarfilled vessel was made as described above (but uninoculated with bacteria). A type $\mathrm{K}$ thermocouple (RS Components Ltd.) was placed in the centre of a cuvette at a radial distance of $r / R=0.5$ from the centre. Temperature change was monitored as the vessel was cooled at $5^{\circ} \mathrm{C}$ and the results compared to mathematical modelling.

\section{Results and discussion}

\subsection{Validation of heat transfer modelling}

Heat transfer from the vessel was modelled using Eq. (12). Experimental validation of this model can be seen in Fig. 2 for the temperature profile at a distance $r / R=0.5$. It can be seen that good agreement between theoretical and experimental results was obtained, with experimental values differing from the model by less than $\pm 1^{\circ} \mathrm{C}$ in all instances. This demonstrates that the present heat transfer model, in which the external heat transfer is assumed to be non-controlling and $\alpha$ for agar to be the same as that for water, is suitable for describing temperature change in the vessel.

\subsection{Growth at static temperatures}

Experiments were conducted at constant temperatures in both liquid broth and solid agar. Typical results for bacterial growth can be seen in Fig. 3 at a fixed temperature of $30^{\circ} \mathrm{C}$. In both cases, the expected sigmoidal growth profiles were observed. Curves were fitted using the model described in Eqs. (6) and (7). An approximately three-fold higher $\mathrm{OD}_{\mathrm{MAX}}$ was observed for growth in liquid culture. This was believed to be because fermentation with agar will, at some stage, switch from aerobic to anaerobic as oxygen becomes depleted within the immediate vicinity of bacterial colonies. This will result in the production of organic acids due to anaerobic fermentation of glucose which will consequently inhibit bacterial growth (Robinson, Wimpenny \& Earshaw, 1991; Wimpenny et al., 1995).

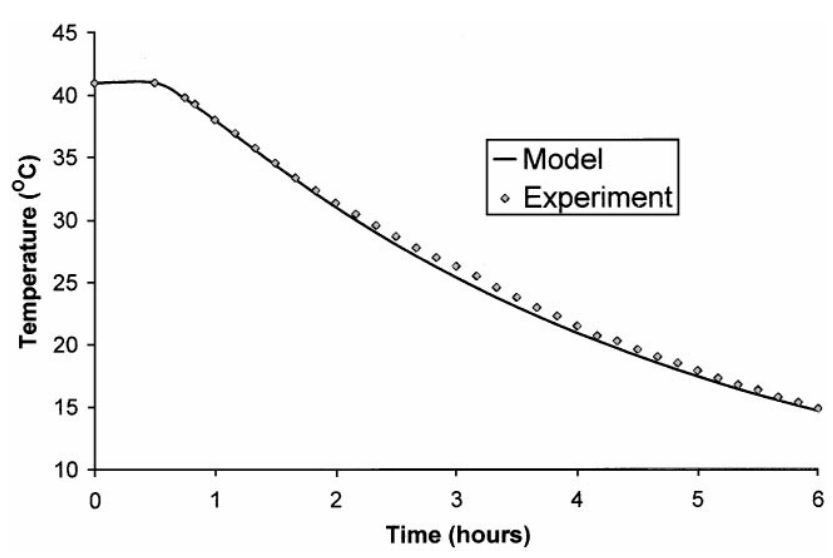

Fig. 2. Temperature change in a glass vessel at $r / R=0.5$ when cooling at $5^{\circ} \mathrm{C}$. 

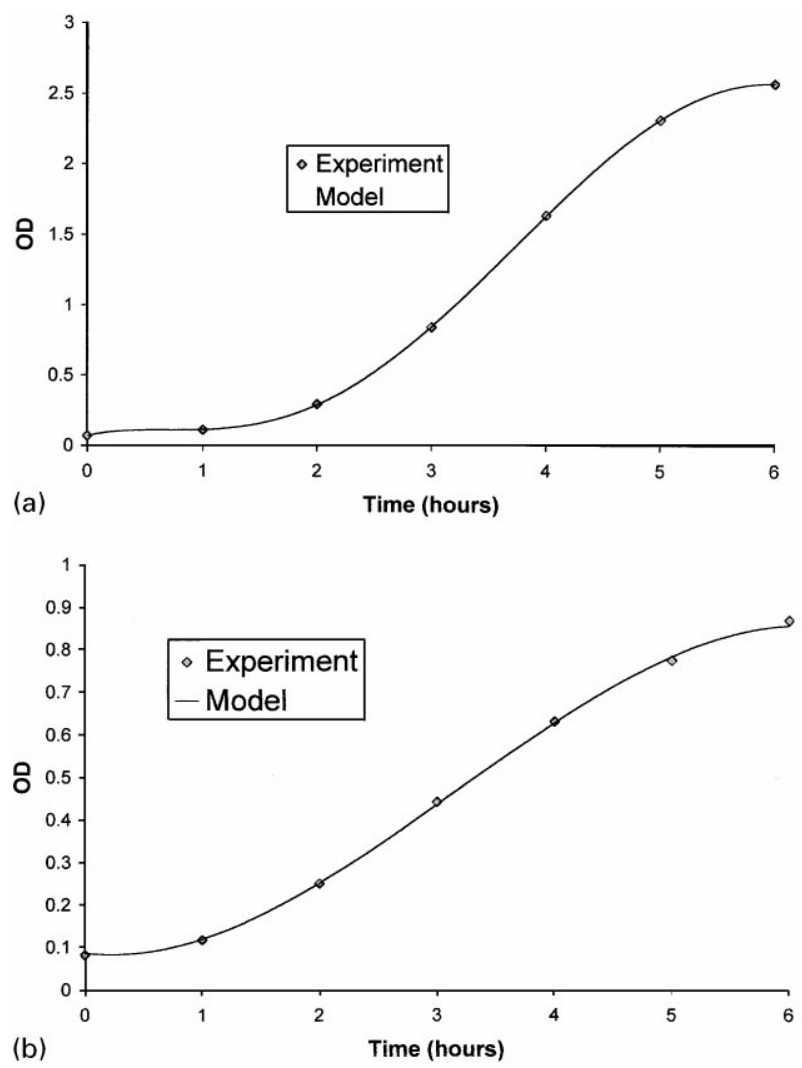

Fig. 3. Growth of E.coli at a static temperature of $30^{\circ} \mathrm{C}$ : (a) in liquid broth and (b) in agar.

Static temperature data from liquid broth and agar experiments were fitted to the model of Baranyi et al. (1995) and the maximum exponential growth rates $(\mu)$ evaluated. Cells in large bacterial colonies embedded in agar will not have the same light scatter properties as freely dispersed cells in liquid culture. However, it has been demonstrated that, for the former, OD is proportional to cell biomass (within limits), for mixtures of both single cells and bacterial chains (Rattanasomboon et al., 1999). Hence over the first two or three cell divisions, which are the most important in the instance of growth in agar, OD increases can be assumed to be proportional to cell biomass. Maximum exponential growth rates were extracted from a regression fit of the model of Baranyi et al. (1995) (see Eqs. (6) and (7)). These can be seen in Fig. 4 for both types of growth medium. Values of $h_{0}$ of 0.9 and 1.4 were used for liquid- and agar-immobilised cultures, respectively. These data show no significant difference in the values calculated for different media $(P<0.05)$. Using data from agar medium, values of $T_{0}$ of 6.7 and $b$ of 0.044 were used in Eq. (8), up to a temperature of $35^{\circ} \mathrm{C}$. At 35 and $40^{\circ} \mathrm{C}$, values of $\mu$ of 1.4 and $1.2 \mathrm{~h}^{-1}$ were calculated, respectively. Hence, for temperature above $35^{\circ} \mathrm{C}$, a mean value of $1.3 \mathrm{~h}^{-1}$ was used. Consistent with other findings in the literature (Krist, Ross \& McMeekin, 1998), the OD $_{\text {MAX }}$ value was found to

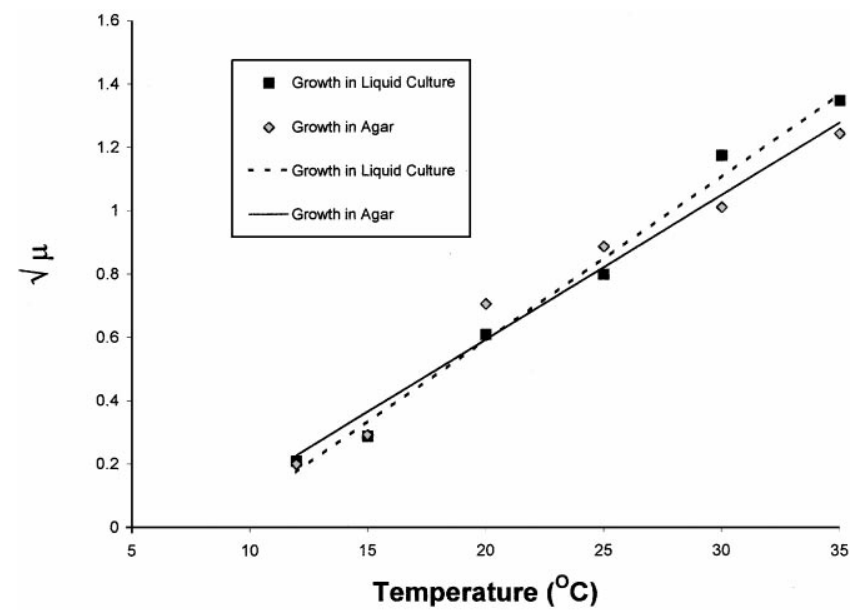

Fig. 4. Maximum exponential growth rates of E.coli as a function of temperature, both in agar and liquid broth. Values extracted from experimental data using the model described by Eqs. (6) and (7).

be relatively insensitive to temperature and was fixed at a value of 0.9 .

The similarity between $\mu$ values observed for growth on liquid and solid medium is not surprising. A number of studies have compared the generation times observed for several different food-borne bacteria, including Brochothrix thermosphacta (McClure, Baranyi, Boogard, Kelly \& Roberts, 1993), Yersina enterocolitica (Sutherland \& Bayliss, 1994), Staphylococcus aureus (Sutherland, Bayliss \& Roberts, 1994) and Listeria monocytogenes (Fernandez, George, Sills \& Peck, 1997), in real foods and liquid media, finding reasonably good agreement. Instances where generation times found for certain food products have not agreed well with liquid culture data, such as eggs or vegetables, can be attributed to the presence of naturally occurring antimicrobial components in the food (Jay, 1996; te Giffel \& Zwietering, 1999). The present study provides additional confirmation that bacteria can grow on solid media at as fast a rate as in liquid media. The maximum cell density reached might be less in solid media, but in examining bacterial spoilage, the maximum cell density is not a very important parameter as food is unacceptable at levels well below this.

\subsection{Model simulations}

Using the model, some simulations were performed to describe the growth of E.coli in the vessel when cooled as described in the experimental section. Data for $r / R$ are presented at a height of $z=0.625 H$. Fig. 5 shows the change in temperature and increase in bacterial numbers (represented by $\mathrm{OD} / \mathrm{OD}_{0}$ ) after different cooling times at $5^{\circ} \mathrm{C}$. Fig. 5(a) shows that only the region of the vessel closest to the exterior is chilled relatively quickly. The effect that this has on bacterial growth is shown in Fig. 5(b). In the outer regions of this vessel, the 


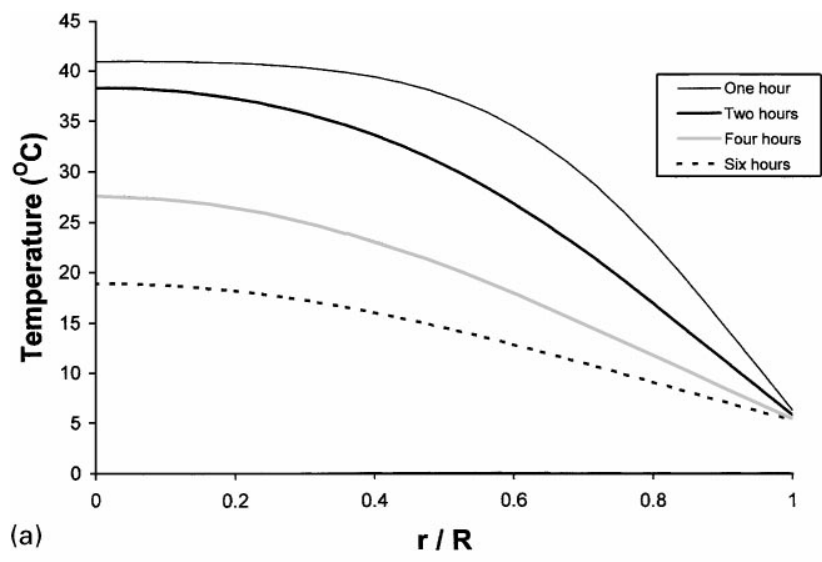

(a)

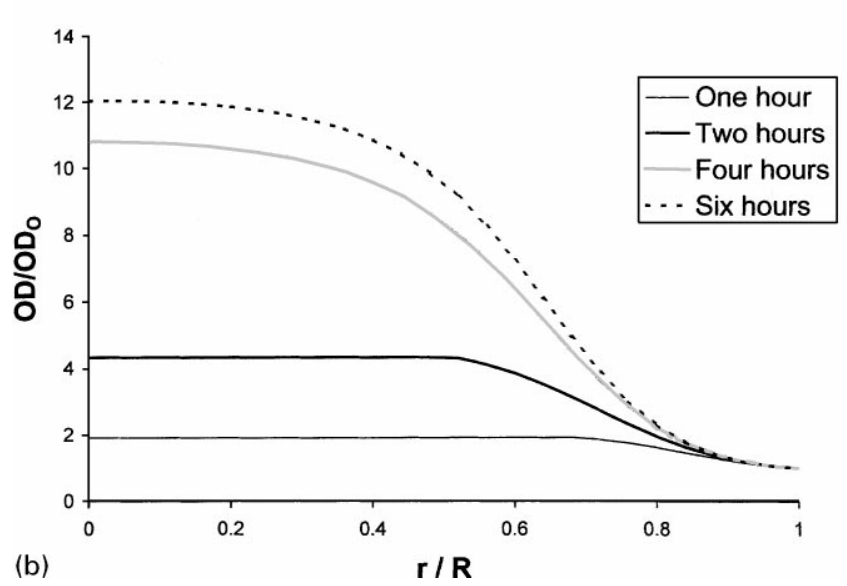

Fig. 5. Model simulation showing (a) temperature and (b) E.coli growth, in a glass vessel as it is externally cooled at $5^{\circ} \mathrm{C}$ for differing time periods.

temperatures are such that little growth occurs. However, after $1 \mathrm{~h}$ of cooling, the bacteria are in the exponential phase of growth across most of the vessel interior. This length of time is clearly important in the cooling of large food products. Over the next $3 \mathrm{~h}$, almost an order of magnitude increase in cell density occurs for parts of the vessel closest to the interior. Hence, for $r / R>0.9$, cell numbers have not even doubled over the cooling process, whereas for $r / R<0.4$ cells are very close to maximum growth rate. Beyond $6 \mathrm{~h}$ of cooling there was little (if any) change in the calculated $\mathrm{OD} / \mathrm{OD}_{0}$ as a function of $r / R$; the whole of the material has cooled below the temperature where growth is significant.

Fig. 6 shows the effect of reducing vessel radius on bacterial growth after $6 \mathrm{~h}$ of cooling, keeping all other dimensions constant. As expected, decreasing vessel size decreases growth as a consequence of much more rapid cooling. After $2 \mathrm{~h}$ of cooling, the centre of the vessel cools by $30^{\circ} \mathrm{C}$ for $R=0.05 \mathrm{~m}$, whereas for $R=0.1145 \mathrm{~m}$, the centre cools only by $4^{\circ} \mathrm{C}$. The results show that bacterial growth is extremely sensitive to vessel radius, the effect of which could (with the appropriate modelling techniques) play an important part in the design of food packaging when considering temperature abuse, cooling or other

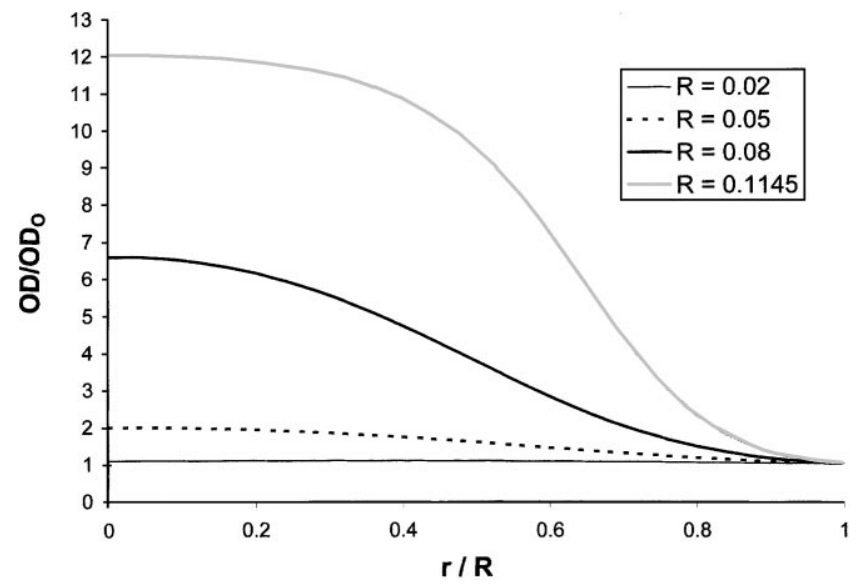

Fig. 6. Model simulations showing the effect of vessel radius on the growth of E.coli in a glass vessel after being externally cooled at $5^{\circ} \mathrm{C}$ for $6 \mathrm{~h}$.

processes in which microbes might find opportunity to grow.

\subsection{Bacterial growth in the vessel when cooled}

Model simulations of bacterial growth in vessels were experimentally validated using E.coli. The vessel was subjected to three different types of cooling regimes, and in each case, experimental OD values were compared to those predicted by model simulations. The results can be seen in Figs. 7-9 for two different external cooling temperatures $\left(5\right.$ and $12^{\circ} \mathrm{C}$ ) and one experiment where the vessel was cooled at $16^{\circ} \mathrm{C}$ for the first $3 \mathrm{~h}$, followed by cooling at $5^{\circ} \mathrm{C}$. For each graph, there appears to be three distinct regions: the centre of the vessel, where OD is not a strong function of cooling temperature, the outside, where cooling is swift and growth minimal, and the region of $r / R \approx 0.7$, where the material spends longer in the critical growth region for the higher cooling temperature. In all three graphs, excellent agreement can be seen

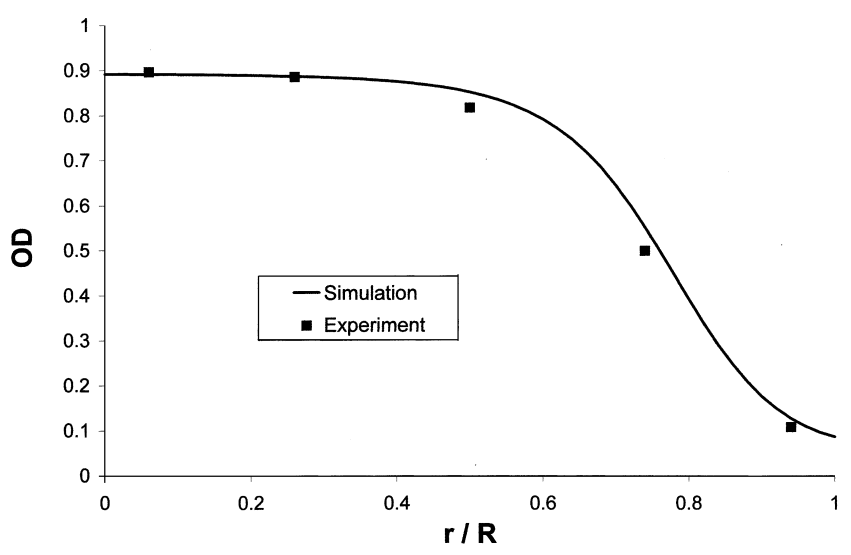

Fig. 7. Growth of E.coli in a glass vessel after cooling at $12^{\circ} \mathrm{C}$ for $12 \mathrm{~h}$. 


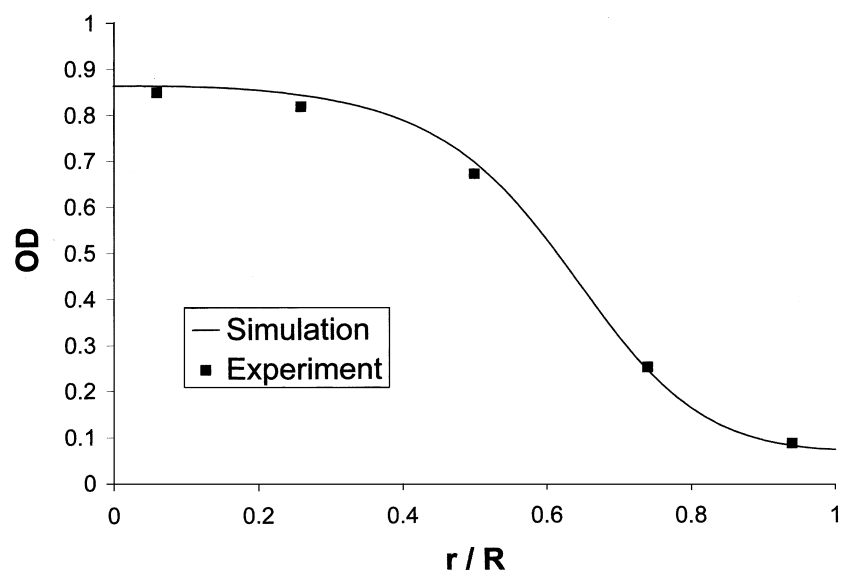

Fig. 8. Growth of E.coli in a glass vessel after cooling at $5^{\circ} \mathrm{C}$ for $12 \mathrm{~h}$.

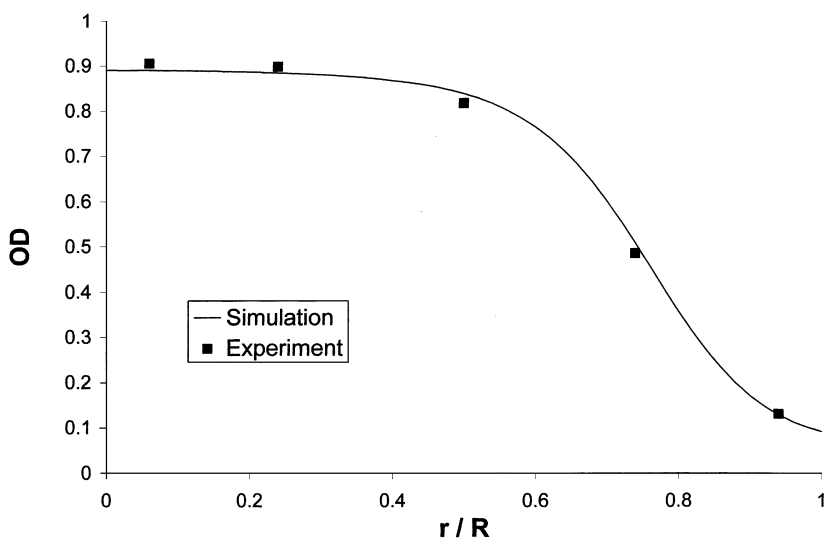

Fig. 9. Growth of E.coli in a glass vessel after cooling at $16^{\circ} \mathrm{C}$ for $3 \mathrm{~h}$ followed by cooling at $5^{\circ} \mathrm{C}$ for $9 \mathrm{~h}$.

between experimental and modelling work. The mean deviation of experimental data from that predicted by model simulations is only $4 \%$.

Cooling the vessel at $12^{\circ} \mathrm{C}$ results in noticeably greater bacterial growth than cooling at $5^{\circ} \mathrm{C}$, particularly at an $r / R$ value of 0.74 . At this point, experimental results show an $\mathrm{OD}$ value of 0.25 when cooling at $5^{\circ} \mathrm{C}$ and 0.50 when cooling at $12^{\circ} \mathrm{C}$. The growth of bacteria is highly sensitive to temperature as demonstrated by Eq. (8), hence it does not come as any surprise to see this difference in Figs. 7 and 8. It has already been demonstrated by Almonacid-Merino and Torres (1993), using simulations, that the shelf-life of foods is highly sensitive to the environmental temperatures to which they are exposed. The authors of that study considered that such numeric modelling may be used in industry to decide whether or not to change conditions such as storage temperatures in distribution facilities.

This study has demonstrated that it is possible to model the growth of E.coli when the temperature to which these bacteria are exposed is varied dynamically. This observation is consistent with others reported in the literature. Ng, Ingraham and Marr (1962) noticed that when the environmental temperature to which exponentially growing E.coli were exposed was suddenly changed, it immediately took on the growth rate associated with the new temperature provided temperature fluctuations were not too great. Gill, Greer and Dilts (1998) inoculated pork meat with E.coli and exposed it to fluctuating temperatures. It was found that the growth of E.coli could be modelled provided temperatures did not go below $7^{\circ} \mathrm{C}$. However, this is the first study to experimentally validate bacterial growth modelling in combination with a heat transfer model of temperature fluctuations within a solid object.

The results from this study suggest that the combination of microbiological and heat transfer modelling can be used to describe bacterial growth in food systems. However, the application of such modelling to systems as complex as food products is far from trivial. For example, the thermal properties of foodstuffs can vary extensively, both between foods and, due to biological variation between different samples of the same foods. This can have a pronounced effect on temperature profiles within foods (Nicolai \& de Baerdemaeker, 1993). However, in spite of the difficulties, a number of studies have demonstrated good agreement between modelled and experimental temperatures during processing of foods. Examples include the sterilisation of canned fish meat (Banga, Alonso, Gallardo \& Perez-Martin, 1993; Hanzawa, Wang, Suzuki \& Sakai, 1998) and the freezing of meat products (de Reinick, 1996; Sanz, de Elvira, Martino, Zaritzky, Otero \& Carrasco, 1999). Also, there are a number of different applications in the food industry where such modelling techniques are potentially useful, even if thermal data are not fully accurate. Cordoba, Cordoba and Jordano (1999) performed detailed microbiological analyses on the commercial processing of chicken croquettes and found increases in the levels of microorganisms after extrusion of the bechamel paste. To ameliorate this problem, rapid cooling of the bechamel paste was recommended; this type of hazard could be identified with the aid of numeric modelling techniques. Guul-Simonsen et al., (1996) performed full-scale experiments on the cooling of raw milk and evaluated bacterial numbers attained from different cooling processes. The use of numerical modelling techniques might, under such circumstances, be able to evaluate which process out of a number of different options is the most efficient, reducing the number of microbiological experiments that have to be conducted.

The above result suggests that it is possible to predict temperature profiles in real foods. However, the mathematical models for microbial growth will have to be validated in real systems. The approach used here requires transparent media to allow optical density to be measured. In real foods another measurement method will be needed. A number of microbial analysis 
techniques now exist in which fluorescence is used as a marker; this technique would be the best way of measuring growth in foods. These techniques will need to be developed to make them fully quantitative. In real foods, mixed bacterial systems are often found; the approach of the food industry is usually to identify the most dangerous organism and to define the processing required on the basis of killing that organism to the required level. More work is needed to develop analytical techniques and to identify the variability of the kinetic models under those circumstances.

\section{Conclusions}

Numerous studies on food products have demonstrated that the generation times of food-borne bacteria can be described as a function of their environmental variables, principally temperature, $\mathrm{pH}$ and water activity. When comparing the growth of E.coli in solid agar (to simulate food) and liquid broth, similar values were found for maximum exponential growth rates, although the maximum OD reached in the case of the former was much less. Using data from E.coli growth in agar, a relatively simple model was set up describing bacterial growth as a function of temperature. This was then used in conjunction with a finite difference heat transfer model describing temperature change in a cylinder, such that the growth of bacteria could be calculated in a vessel as it was being cooled. Model simulations were compared to experimental data and excellent agreement was found between the two. It is felt that such modelling has potential applications in the food industry, where it could help reduce the number of microbiological experiments required in assessing process safety.

\section{Notation}

$A(t) \quad$ variable defined by Eq. (7), s

$b \quad$ regression coefficients, $\mathrm{C}^{-1}$

$h_{0} \quad$ product of $\mu$ and the lag time, dimensionless

$h \quad$ heat transfer coefficient, $\mathrm{W} \mathrm{m}^{-2} \mathrm{C}^{-1}$

$H \quad$ height, $\mathrm{m}$

$K_{P} \quad$ Michaelis-Menten-type constant, mol cell ${ }^{-1}$

OD optical density, dimensionless

$\mathrm{OD}_{0} \quad$ optical density before growth starts, dimensionless

$\mathrm{OD}_{\mathrm{MAX}}$ maximum optical density attained in the stationary phase, dimensionless

$P(t) \quad$ per cell quantity of a substance, $\mathrm{mol} / \mathrm{cell}$

$q_{H} \quad$ heat flux, $\mathrm{W} \mathrm{m}^{-2}$

$q(t) \quad$ used to characterise the physiological state of the culture, dimensionless

$r \quad$ radial co-ordinate, $\mathrm{m}$

$R_{T} \quad$ external radius of vessel, $\mathrm{m}$
$T \quad$ temperature, ${ }^{\circ} \mathrm{C}$

$T_{0} \quad$ temperature value specific to bacteria (Eq. (8)), ${ }^{\circ} \mathrm{C}$

$T_{L} \quad$ limiting temperature for applicability of Eqs. (8) and (9), ${ }^{\circ} \mathrm{C}$

$v \quad$ constant specific growth rate, $\mathrm{s}^{-1}$

$y \quad \ln \mathrm{OD}$, dimensionless

$z \quad$ axial co-ordinate, $\mathrm{m}$

$\alpha \quad$ thermal diffusivity, $\mathrm{m}^{2} \mathrm{~s}^{-1}$

$\mu \quad$ maximum exponential growth rate, $\mathrm{s}^{-1}$

\section{Acknowledgements}

Their project was sponsored by the Biotechnology and Biological Sciences Research Council (UK). The work is a collaboration between the Universities of Birmingham of Reading; the assistance of Dr. Bernard Mackey and colleagues at Reading is gratefully acknowledged.

\section{References}

Adams, M. R., Little, C. L., \& Easter, M. C. (1991). Modelling the effect of $\mathrm{pH}$, acidulant and temperature on the growth rate of Yersina enterocolitica. Journal of Applied Bacteriology, 71, 65-71.

Adams, M. R., \& Moss, M. O. (1995). Food microbiology and public health In: Food microbiology, (pp. 136-155). Cambridge: The Royal Society of Chemistry (Chapter 6).

Almonacid-Merino, S. F., \& Torres, J. A. (1993). Mathematical models to evaluate temperature abuse effects during distribution of refrigerated solid foods. Journal of Food Engineering, 20, 223-245.

Banga, J. R., Alonso, A. A., Gallardo, J. M., \& Perez-Martin, R. I. (1993). Mathematical modelling and simulation of the processing of anisotropic and non-homogeneous conduction-heated canned foods: Application to canned tuna. Journal of Food Engineering, 18, 369-387.

Baranyi, J., Jones, A., Walker, C., Kaloti, A., Robinson, T. P., \& Mackey, B. M. (1996). A combined model for growth and subsequent thermal inactivation of Brochothrix thermosphacta. Applied Environmental Microbiology, 62, 1029-1035.

Baranyi, J., Roberts, T. A., \& McClure, P. (1993). A non-autonomous differential equation to model bacterial growth. Food Microbiology, $10,43-59$.

Baranyi, J., Robinson, T. P., Kaloti, A., \& Mackey, B. M. (1995). Predicting the growth of Brochothrix thermosphacta at changing temperature. Interational Journal of Food Microbiology, 27, 61-75.

Begot, C., Desnier, I., Daudin, J. D., Labadie, J. C., \& Lebert, A. (1996). Recommendations for calculating growth parameters by optical density measurements. Journal of Microbiological Methods, 25, 225-232.

Bellara, S. R., Fryer, P. J., McFarlane, C. M., Thomas, C. R., Hocking, P. M., \& Mackey, B. M. (1999). Vizualization and modelling of the thermal inactivation of bacteria in a model food. Applied Environmental Microbiology, 65, 3095-3099.

Buchanan, R. L., Bagi, L. K., Goins, R. V., \& Phillips, J. G. (1993). Response surface models for the growth kinetics of Escherichia coli 0157:H7. Food Microbiology, 10, 303-315.

Communicable Disease Surveillance Centre, Public Health Laboratory Service (1998). Communicable Disease Report Weekly, 8, 14-20. 
Cordoba, M. G., Cordoba, J. J., \& Jordano, R. (1999). Microbiological hazards during processing of croquettes. Journal of Food Safety, 19, $1-15$.

Coulson, J. M., \& Richardson, J. F. (1990). Heat transfer. In J. M. Coulson, J. F. Richardson, J. R. Backhurst \& J. H. Harker (Eds.), Chemical engineering, vol. 1, (3rd ed.) (pp. 167-267). Oxford: Pergammon Press.

Dalgaard, P. (1995). Modelling of microbial activity and prediction of shelf-life for packed fresh fish. International Journal of Food Microbiology, 26, 305-317.

Daughtry, B. J., Davey, K. R., \& King, K. D. (1997). Temperature dependence of growth kinetics of food bacteria. Food Microbiology, 14, 21-30.

de Reinick, A. C. R. (1996). Average and centre temperature vs time evaluation for freezing and thawing rectangular foods. Journal of Food Engineering, 30, 299-311.

Dickson, J. S., Siragusa, G. R., \& Wray, J. E. (1992). Predicting the growth of Salmonella typhimurium on Beef by using the temperature function integration technique. Applied Environmental Microbiology, 58, 3482-3487.

Fernandez, P. S., George, S. M., Sills, C. C., \& Peck, M. W. (1997). Predictive model of the effect of $\mathrm{CO}_{2}, \mathrm{pH}$, temperature and $\mathrm{NaCl}$ on the growth of Listeria monocytogenes. International Journal of Food Microbiology, 37, 37-45.

Fu, B., Taoukis, P. S., \& Labuza, T. P. (1991). Predictive microbiology for monitoring spoilage of dairy products with time-temperature integrators. Journal of Food Science, 56, 1209-1215.

Gibson, A. M., Bratchell, N., \& Roberts, T. A. (1988). Predicting microbial growth: Growth responses of Salmonellae in a laboratory medium as affected by $\mathrm{pH}$, sodium chloride and storage temperature. International Journal of Food Microbiology, 6, 155-178.

Gill, C. O. (1996). Cold storage temperature fluctuations and predicting microbial growth. Journal of Food Protection (Suppl.), 43-47.

Gill, C. O., Friske, M., Tong, A. K. W., \& McGinnis, J. C. (1994). Assessment of the hygiene characteristics of a process for the distribution of processed meats, and of storage conditions at retail outlets. Food Research International, 28, 131-138.

Gill, C. O., Greer, G. G., \& Dilts, B. D. (1998). Predicting the growth of Escherichia coli on displayed pork. Food Microbiology, 15, 235-242.

Griffiths, M. W. (1994). Predictive modelling: Applications in the dairy industry. International Journal of Food Microbiology, 23, 305-315.

Guul-Simonsen, F., Christiansen, P. S., Edelsten, D., Kristiansen, J. R., Madsen, N. P., Nielsen, E. W., \& Peterson, L. (1996). Cooling, storing and quality of raw milk. Acta Agriculturae Scandinavica. Section A - Animal Science, 46, 105-110.

Hanzawa, T., Wang, Q. H., Suzuki, M., \& Sakai, N. (1998). Numerical analysis of slowest heating or cooling point in a canned food in oil. Journal of Chemical Engineering Japan, 31, 451-455.

Jay, J. M. (1996). Foodborne gastroenteritis caused by Escherichia coli. In Model food microbiology (pp. 527-543). New York: Chapman \& Hall.

Krist, K. A., Ross, T., \& McMeekin, T. A. (1998). Final optical density and growth rate; effects of temperature and $\mathrm{NaCl}$ differ from acidity. International Journal of Food Microbiology, 43, 195-203.

Li, K. Y., \& Torres, J. A. (1993). Microbial growth estimation in liquid media exposed to temperature fluctuations. Journal of Food Science, 58, 644-648.

McClure, P. J., Baranyi, J., Boogard, E., Kelly, T. M., \& Roberts, T. A. (1993). A predictive model for the combined effect of $\mathrm{pH}$, sodium chloride and storage temperature on the growth of Brochothrix thermosphacta. International Journal of Food Microbiology, 19, 161-178.

McClure, P. J., Blackburn, C. D. W., Cole, M. B., Curtis, P. S., Jones, J. E., Legan, J. D., Ogden, I. D., Peck, M. W., Roberts, T. A., Sutherland, J. P., \& Walker, S. J. (1994a). Modelling the growth, survival and death of microorganisms in foods: The UK Food Micromodel approach. International Journal of Food Microbiology, 23, 265-275.

McClure, P. J., Cole, M. B., \& Davies, K. W. (1994b). An example in the stages of the development of a predictive mathematical model for microbial growth: The effects of $\mathrm{NaCl}, \mathrm{pH}$ and temperature on the growth of Aeromonas hydrophila. International Journal of Food Microbiology, 23, 359-375.

McMeekin, T. A., Ross, T., \& Olley, J. (1992). Application of predictive microbiology to assure the quality and safety of fish and fish products. International Journal of Food Microbiology, 15, 13-32.

Mitchell, G. A., Brocklehurst, T. F., Parker, R., \& Smith, A. C. (1994). The effect of transient temperatures on the growth of Salmonella typhimurium LT2. I: Cycling within the growth region. Journal of Applied Bacteriology, 77, 113-119.

Ng, H., Ingraham, J. L., \& Marr, A. G. (1962). Damage and depression in Escherichia coli resulting from growth at low temperatures. Journal of Bacteriology, 84, 331-339.

Nicolai, B. M., \& de Baerdemaeker, J. (1993). Computation of heat conduction in materials with random variable thermophysical properties. International Journal of Numerical Methods in Engineering, 36, 523-536.

Perry, R. H., \& Green, D. (1984). Perry's chemical engineer's handbook. (6th ed.). Singapore McGraw-Hill.

Raithby, G. D., \& Hollands, K. G. T. (1998). Natural convection. In W. M. Rohsenow, J. P. Hartnett, \& Y. I. Cho (Eds.), Handbook of heat transfer (3rd ed). New York: McGraw-Hill (Chapter 4).

Ratkowsky, D. A., Lowry, R. K., McMeekin, T. A., Stokes, A. N., \& Chandler, R. E. (1983). Model for bacterial culture growth throughout the entire biokinetic temperature range. Journal of Bacteriology, 154, 1222-1226.

Ratkowsky, D. A., Olley, J., McMeekin, T. A., \& Ball, A. (1982). Relationship between temperature and growth rate of bacterial cultures. Journal of Bacteriology, 149, 1-5.

Rattanasomboon, N., Bellara, S.R., Harding, C.L., Fryer, P.J., Thomas, C.R., Al-Rubeai, M., \& McFarlane, C.M. (1999). Growth and enumeration of the meat spoilage bacterium Brochothrix thermosphacta International Journal of Food Microbiology, 51 145-158.

Robinson, T.P., Wimpenny, J.W.T., \& Earshaw, R.G. (1991). pH gradients through colonies of Bacillus cereus and the surrounding agar Journal of General Microbiology, 137 2885-2889.

Sanz, P. D., de Elvira, C., Martino, M., Zaritzky, N., Otero, L., \& Carrasco, J. A. (1999). Freezing rate simulation as an aid to reducing crystallization damage in food. Meat Science, 52, 275-278.

Skinner, G. E., Larkin, J. W., \& Rhodehamel, E. J. (1994). Mathematical modelling of bacterial growth: A review. Journal of Food Safety, 14, 175-217.

Sutherland, J.P., \& Bayliss, A.J. (1994). Predictive modelling of growth of Yersinia enterocolitica: The effects of temperature, $\mathrm{pH}$ and sodium chloride. International Journal of Food Microbiology, 21, 197-215.

Sutherland, J.P., Bayliss, A.J., \& Roberts, T.A. (1994). Predictive modelling of growth of Staphylococcus aureus: The effects of temperature, $\mathrm{pH}$ and sodium chloride. International Journal of Food Microbiology, 21, 217-236.

te Giffel, M.C., \& Zwietering, M.H. (1999). Validation of predictive models describing the growth of Listeria monocytogenes. International Journal of Food Microbiology, 46, 135-149.

Walls, I., \& Scott, V.N. (1996). Validation of predictive mathematical models describing the growth of Escherichia coli 015:H7 in raw ground beef. Journal of Food Protection, 59, 1331-1335.

Wimpenny, J. W. T., Leistner, L., Thomas, L. V., Mitchell, A. J., Katsaras, K., \& Petra, P. (1995). Submerged bacterial colonies within food and model systems: Their growth, distribution and interactions. International Journal of Food Microbiology, 28, 299-315. 
Zwietering, M. H., Jongenburger, I., Rombouts, F. M., \& van't Riet, K. (1990). Modelling of the bacterial growth curve. Applied Environmental Microbiology, 56, 1875-1881.

Zwietering, M. H., de Koos, J. T., Hasenack, B. E., de Wit, J. C., \& van't Riet, K. (1991). Modelling of bacterial growth as a function of temperature. Applied Environmental Microbiology, 57, 1094-1101.
Zwietering, M. H., de Wit, J. C., Cuppers, H. G. A. M., \& van't Riet, K. (1994). Modelling of bacterial growth with shifts in temperature. Applied Environmental Microbiology, 60, 204-213.

Zwietering, M.H., de Wit, J.C., \& Notermans, S. (1996). Application of predictive microbiology to estimate the number of Bacillus cereus in pasterurised milk at the point of consumption. International Journal of Food Microbiology, 30, 55-70. 